\title{
Evaluating the Yield Response of Maize \\ (Zea mays L.) and Rice (Oryza sativa L.) to Future Climate Variability in The Gambia
}

\author{
Ebrima Sonko (Corresponding author) \\ WASCAL Climate Change and Land Use Program, Department of Civil Engineering, Kwame \\ Nkrumah University of Sciences and Technology, Kumasi, Ghana, Tel: (+220) 7711659 or \\ (+233) 501592129, Email: sonkojeleng78@gmail.com \\ Sampson K. Agodzo \\ Department of Agriculture and Biosystems Engineering, Kwame Nkrumah University of \\ Science and Technology, Kumasi, Ghana, Tel: (+233) 208165505, Email: skagodzo7@usa.net \\ Philip Antwi-Agyei \\ Department of Environmental Science, Kwame Nkrumah University of Science and \\ Technology, Kumasi, Ghana, Tel: (+233) 505255247, Email: philiantwi@yahoo.com
}

Received: March 3, 2019 Accepted: April 3, $2019 \quad$ Published: April 15, 2019

doi:10.5296/jas.v7i2.14664

URL: https://doi.org/10.5296/jas.v7i2.14664

\begin{abstract}
Climate change and variability impact on staple food crops present a daunting challenge in the $21^{\text {st }}$ century. The study assesses future climate variability on maize and rice yield over a 30-year period by comparing the outcomes under two GCM models, namely, CSIRO_RCP4.5 and NOAA_RCP4.5 of Australia's Commonwealth Scientific and National Oceanic and Atmospheric Administration respectively. Historical climate data and yield data were used to establish correlations and then subsequently used to project future yields between 2021 and 2050. Using the average yield data for the period 1987-2016 as baseline yield data, future yield predictions for 2021-2030, 2031-2040 and 2041-2050 were then compared with the baseline data. The results showed that the future maize and rice yield would be vulnerable to climate variability with CSIRO_RCP4.5 showing increase in maize yield whilst CSIRO_RCP4.5 gives a better projection for rice yield. Furthermore, the results estimated the percentage mean yield gain for maize under CSIRO_RCP4.5 and NOAA_RCP4.5 by about $17 \%, 31 \%$ and $48 \%$ for the period 2021-2030, 2031-2040 and 2041-2050 respectively. Mean rice yield lossess of $-23 \%,-19 \%$ and $-23 \%$ were expected for the same period respectively. The study recommended the use of improved rice and maize cultivars to offset the negative effects of climate variability in future.
\end{abstract}


Keywords: climate variability, maize, rice, projection, yield, model

\section{Introduction}

In the begining of the $21^{\text {st }}$ century, Scientists were worried about climate change which they believed was caused by antropogenic activities leading to global warning (Sissoko et al., 2011). As reported by IPCC (2007), "climate change refers to a change in the state of the climate that can be identified by changes in the mean or variability of its properties and that persists for an extended period, typically decades or longer". Previous studies reported nearly $90 \%$ of crop production in Sub-Saharan comes from rainfed agriculture (Godfray et al., 2010; Conceição et al., 2016). Agricultural production since 1988 has been faced with interrupted consequences of climate variables in The Gambia such as decline in rainfall and increase in temperature (Sanneh et al., 2014). Since the 1960s, variation in climate in The Gambia was attributed to fluctuation of rainfall distribution, extreme temperature, storms, drought and flooding, this has exacerbated household food security.

Many researchers and development practisonners tried to model the future climate variability on crop production using different explanatory variables which enhanced production. Wei et al. (2009) used Ricardian method to model the economic influence of climate change on crop production in Ethiopia. The result established that a shift in normal temperature will have a negative influence on crop yield hence impacted on the net revenue after harvest. In contrary, Nakano et al. (2014) used three models (cross-sectional, crop simulation and response function) to compare agricultural output to the effects of climate variability in Japan. The results showed that climate change will increase agricultural production from 2 to $4 \%$. However, the models showed a disparity of yield in terms of geographical location. The evaluation of Asian rice to the effects of climate change was conducted by Kropff et al. (1997) using SIMRIW rice crop simulation model. The study reported that, increase in $\mathrm{CO}_{2}$ concentration in the atmosphere in higher temperature can boost rice yield. In contrast, below average temperature may show a negative effect on rice yield. Although, yield projections can help to determine the levels at which a system can be exposed to different biophysical and climate variables.

Zhijuan et al. (2012) simulated maize phenology and yield using APSIM-Maize model to investigate the impact of climate change on maize yield. It was observed from the results that, on farm maize yield will dropped by $30 \%$ at a seasonal rainfall of $(<500 \mathrm{~mm})$. In a similar study, Lobell and Burke (2010) projected maize yield with a "widely used process-based model CERES-Maize to simulate historial yields, and then fit statistical regressions to the simulated data. The results suggested that statistical models, as compared to CERES-Maize, represent a useful imperfect tool for projecting future yield responses". Using the simplified process-based model, Clark et al. (2016) and Sheahan and Barrett (2017) describes potentials to examine distribution of parameter values from data on yields of rice and maize. The results showed uncertainties of climate variables to predict future crop yield, reporting that climate variables exceeded those in the calibration period. On-farm production in The Gambia have been under pressure due to uncertainties of the growing ecologies to climate change and variability. The farming households food security is being threaten due to interrupted weather events leading to poverty in Sub-Saharan Africa (Nigatu et al., 2017). 
Few studies in The Gambia focus on the productivity of major crops and how they are impacted by historical climate change (Hayes et al., 1997; Akon-yamga et al., 2011). Bojang et al. (2016) "formulated a Linear Programming model with the aim to maximize the farmers' net profit under a set of contraints (plant area and water)". Their findings revealed that, about $50 \%$ of annual revenue of the farm can be achieved through optimum water use efficiency. In a different study, Al-Amin et al. (2016) concluded that by 2100, agriculture in Sub-Saharan Africa including The Gambia may likely face yield reduction and low GDP due to climate change. Climate change and variability can cause a total economic failure, if a system depends immensely on this primary driver for source of revenue (Lobell and Field, 2007). This study aims to determine future yield of staple food crops (rice and maize) to future consequences of climate variability using simulated data. To achieved this aim, the following analyses will be carried out :

(i) Evaluating the effect of historical climate variables on the historical rice and maize yields.

(ii) Estimating the effects of future climate variables on the yields of rice and maize

(iii) Evaluating the decadal percentage change on future crop yields using different climate scnerios

\section{Literature Review}

During the $21^{\text {st }}$ century, many efforts have been put into projection studies of the likely effect of climate change and variability on major staple food production. Empirically, most of these studies have been limited to Asian countries (see for instance Nepal: Jha et al., 2019; Taiwan: Shiu and Chuang, 2019; China: Sheng and Song, 2019). However with regards to the choice of climate variables, several studies considered the effect of few climate variables such as temperature and precipitation without taking into account sunshine duration and relative humidity with the exception of (Maracchi et al., 2005). In Ethiopia, Kisekka et al. (2015) projected that maize yields could increase in the near future by (1.7 to $2.9 \%$ across models and RCPs), with uncertainty increasing towards mid-century (0.6 to $4.2 \%$ ) as predicted by 20 (GCMs) and 2 (RCPs; RCP4.5 and RCP8.5). Waha et al. (2013), used a dynamic global vegetation model to simulate maize yields under current and future climatic condition for two 10-year periods 2056-2065 and 2081-2090 respectively. The results showed that, increase in temperature will lead to maize yield reductions of 3 to $20 \%$, and a reduction of precipitation will causes decreases in maize yield in sub-Saharan Africa.

Similarly, Awoye et al. (2017) used probabilistic crop models, a gridded observational data set, and a high-resolution regional climate model to project potential impacts of climate change on nine important crops in Benin. The results of the simulated yields indicated that, pineapple, maize, groundnuts, cassava and cowpeas would face harmful effects of yield reduction in the range of 11 to $33 \%$ by 2050, whereas sorghum, yam, cotton and rice will benefit from climate change with an average yield gain of 10 to $39 \%$. In a similar study in Ghana, Srivastava et al. (2018) estimated the effects of climate variables on potential maize productivity using two (RCPs) namely RCP 4.5 and RCP 8.5 from the GFDL-ESM2M, 
GISS-E2-H, and HadGEM2-ES, (GCMs). The results revealed that, maize yield is projected to increase by $57 \%$ and $59 \%$ respectively under HadGEM2-ES (RCP 8.5) in the time horizon 2030 and inconsistent yield ranging from $183.6 \mathrm{~kg} \mathrm{ha}^{-1}$ under HadGEM2-ES (RCP 8.5 ) by time horizon 2080. Notwithstanding, most of the other projection studies in West Africa considered precipitation and temperature as climate variables to project staple food crops such as maize without taking into account sunshine duration and relative humidity (for instance Burkina Faso, Waongo et al., 2015; Nigeria, Mereu et al., 2015; Mali, Traore et al., 2017).

Furthermore, Gupta and Mishra (2019) quantify the climate change impact on rice yield in India using process-based Crop Simulation Model (CSM)-CERES-Rice fed and Global Climate Models (GCMs) for four expected climatic scenarios (RCP 2.6, 4.5, 6.0 and 8.5). The results showed a spatial rice yield in India taking all used GCM-RCP combinations in consideration is expected to vary from 1.2 to $8.8 \%, 0.7$ to $12.6 \%$ and -2.9 to $17.8 \%$ due to the expected climate change in 2020s, 2050s and 2080s, respectively. In a similar study, Oort and Zwart (2018) quantify the possible effects of climate change on rice production in Africa using simulated rice yields for 4 RCP climate change scenarios. The projection result revealed that, without adaptation, shortening of the growing period due to higher temperatures had a negative impact on yields by $-24 \%$ and decrease by $-15 \%$ with adaptation in RCP 8.5 in 2070 compared with the baseline year 2000.

In conclusion, from these various estimates, it is evidence that a couple of predictions have been established on the likely effect of climate change on the production of maize and rice. Yet there are no General Circulation Models (GCMs) identified to assess future impact of climate change on maize and rice yields in most African countries specifically The Gambia. We choose maize and rice as an example crop as it is the most important staple food crop in The Gambia in terms of nutrition security and harvested area.

\section{Materials and Methods}

\subsection{Study Area and Source of Data}

The study was conducted in Lower River Region of The Gambia which is located between latitudes $13^{0} 34^{\prime} 0^{\prime \prime} \mathrm{N}$ and longitude $14^{0} 47^{\prime} 0$ " $\mathrm{W}$ (Figure 1). The region has an agrarian economy and more than half of its inhabitants are directly or indirectly involved in crop production. It has a Sudano-Sahelian climate characterized by a short rainy season from June to October. Mean annual rainfall varies from $900 \mathrm{~mm}$ in the South West to about $600 \mathrm{~mm}$ in the North East. Mean temperatures ranging from $25^{\circ} \mathrm{C}$ to $28^{\circ} \mathrm{C}$ are generally higher in the Eastern part of the country. It has a total land surface area of $1,618 \mathrm{~km}^{2}$ (GBoS, 2013). 


\section{Macrothink}

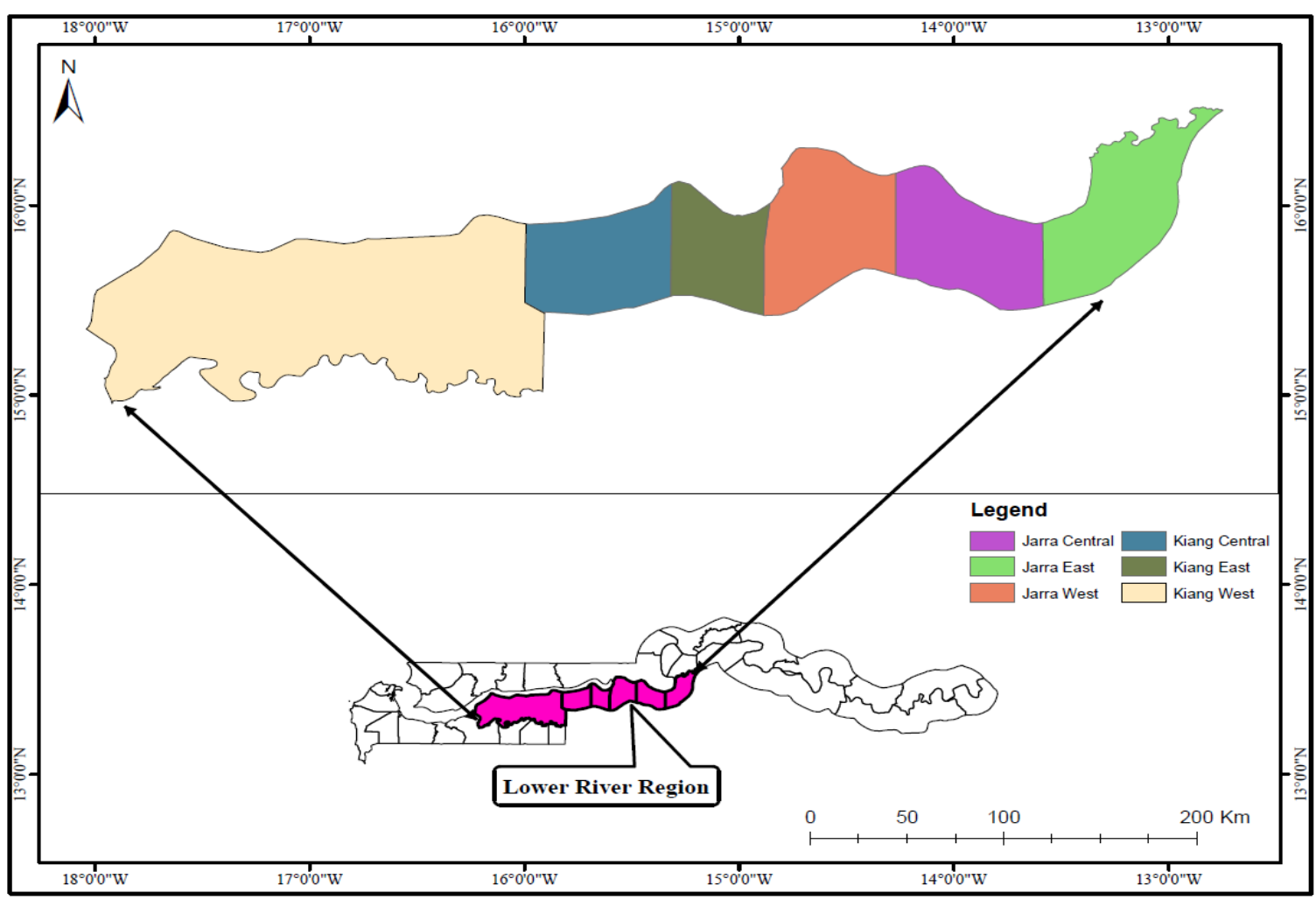

Figure 1. Map of The Gambia showing different districts in Lower River Region

\subsection{Climate and Crop Yield Data}

The historical climate data used to generate the model in this study was obtained from Department of Water Resources of The Gambia. The historical data used was from 1987 to 2016 in Jenoi weather station. The time series crop yield data was obtained from the Department of Planning Services of Agriculture for the same period 1987 to 2016.

\subsubsection{Model Selection Approaches for Projected Climate Data}

Two models were chosen from the GCM models that performed best in the study weather station, CSIROMk3.0 provided by Australia's Commonwealth Scientific and NOAA-ESM2M-RCA4 provided by National Oceanic \& Atmospheric Administration (NOAA) offices in America. The projected climate data was downloaded from CORDEX website (ESGF). The data was bias corrected using CMhyd software using Distribution mapping command (Lobell and Gourdji, 2012).

\subsubsection{Regression Model for Yield Prediction}

The yield response of each crop to annual precipitation, average minimum and maximum temperatures, average relative humidity and average sunshine duration using statistical models were generated from 1987 to 2016 . Statistical models were used in this study due to inadequate process-based models for staple crops considered in this study. The most important use of models is their strength to account for a wide variety of mechanisms that affect yields in a changing weather. The statistical model used in this study was modified from (Lobell and Gourdji, 2012). Firstly, annual rainfall, annual average minimum and 
maximum temperature, relative humidity and sunshine duration were computed for Jenoi weather station for the period 1987 to 2016 . For the yields of rice and maize, the region-wise time series was computed by taking the average yield of each crop.

The yield models were tested by estimating yield from the observed data using the period from 1997-2006 and t-test was run to compare the means. It is assumed that when there is significant difference between the means, the model will not be good to project future yield.

Table 1. Statistical yield models used for yield projection in this study

\begin{tabular}{clc}
\hline Crop & Equation & $\mathrm{R}^{2}$ \\
\hline Rice & $Y r=-5433.12+0.091986 r f-107.217 t \mathrm{~min}+283.6062 t \mathrm{max}-21.8381 r h-82.3316 \mathrm{shd}$ & 0.62 \\
& & \\
Maize & $Y m=-5142.24-0.36936 r f+13.39952 t \mathrm{~min}+182.971 t \mathrm{max}+77.52232 r h-586.186 \mathrm{shd}$ & 0.51 \\
\hline
\end{tabular}

$Y$ represent yield $(\mathrm{kg} / \mathrm{ha})$, rf rainfall, tmin minimum temperature, tmax maximum temperature, rh Relative humidity, shd Sunshine duration

Percentage yield losses of maize and rice were computed using equation 1

$$
\% \text { Change }=\frac{P y-B y}{B y} \times 100 \% \ldots \ldots \ldots \text { Equation } 1
$$

Where:

Py $=$ Predicted yield $\quad$ By $=$ Baseline yield

\subsection{Data Analysis}

The regression models were applied to the annual simulation of rainfall, minimum and maximum temperatures, relative humidity and sunshine duration from the two GCMs for 2021-2050 to the assess influence of future climate change on rice and maize yields. The percentage yield loss was analysed using excel version 2016 during 30 year period from 2021-2050.

\section{Results}

\subsection{Effects of Future Climate Variability on the Yield of Maize and Rice}

Historically, the actual maize yield showed a decreasing trend for the past 30 years (1987-2016) Figure 2. The highest average baseline maize yield (1761 kg/ha) was observed in 2001 whilst the lowest average maize yield $692 \mathrm{~kg} / \mathrm{ha}$ was in 2015. However, the coefficient of determination showed that about $19 \%$ of the yield decline is due to climate variability, indicating that other non-climate variable also account for yield reduction. Furthermore, the future projection of maize yield showed a contrasting trend as the projection 


\section{Macrothink}

period increases, under both scnerios from the trend curve of Figure 3. The average annual yield under CSIRO_RCP4.5 showed the highest increase of $2232 \mathrm{~kg} / \mathrm{ha}$ in 2050 and the lowest was observed in 2024 (631 kg/ha). Contrary, the projection for NOAA_RCP4.5 showed highest record $1974 \mathrm{~kg} / \mathrm{ha}$ in 2049 whilst the lowest yield was recorded in 2038 (292 $\mathrm{kg} / \mathrm{ha}$ ). The trends showed some consistency for the 2 GCM models. However, in 2038, while one model predicts a rise in yield of maize, the other predicted a fall.

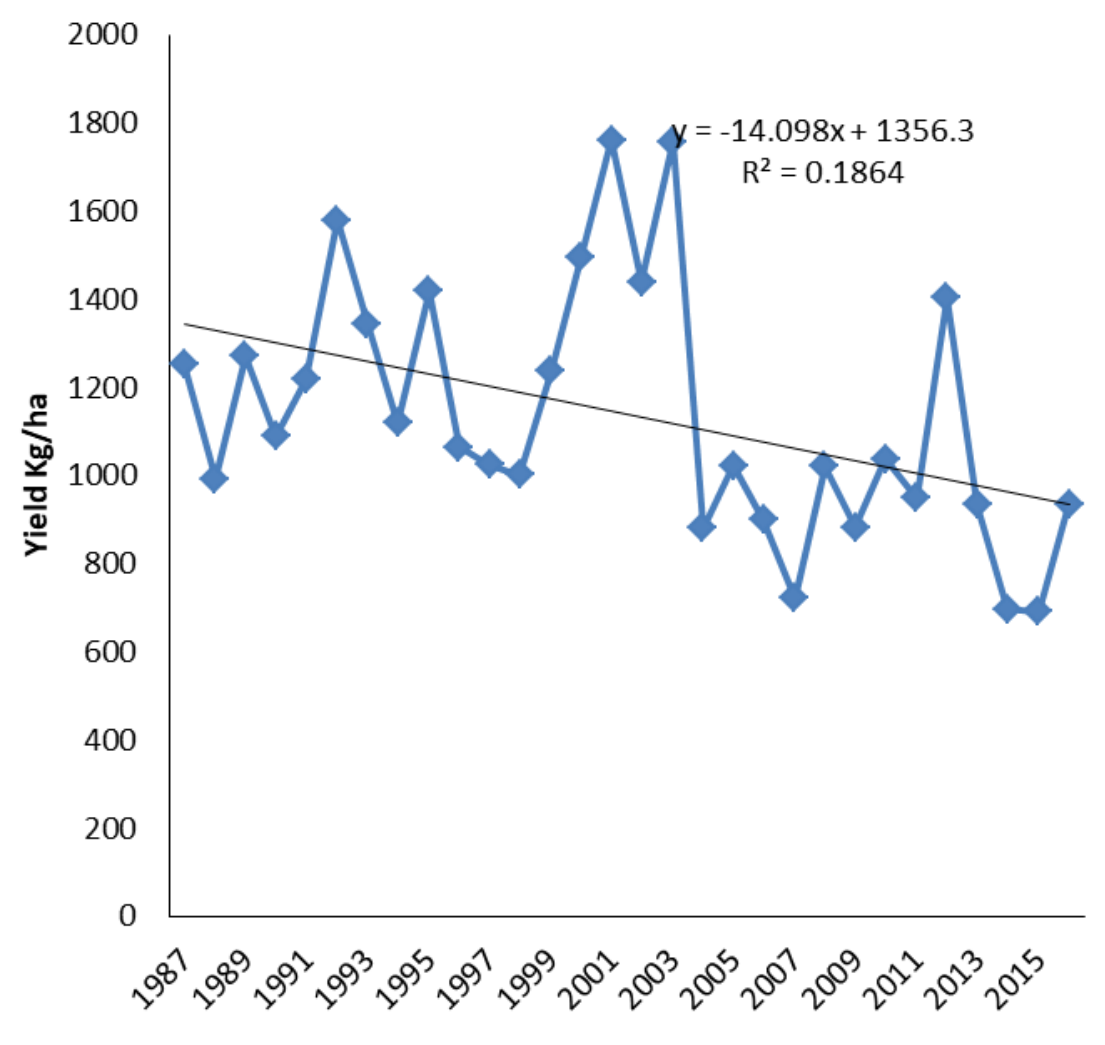

Figure 2. Actual and estimated maize yield due to annual trends in historical rainfall, minimum and maximum temperatures, relative humidity and sunshine duration from 1987-2016 


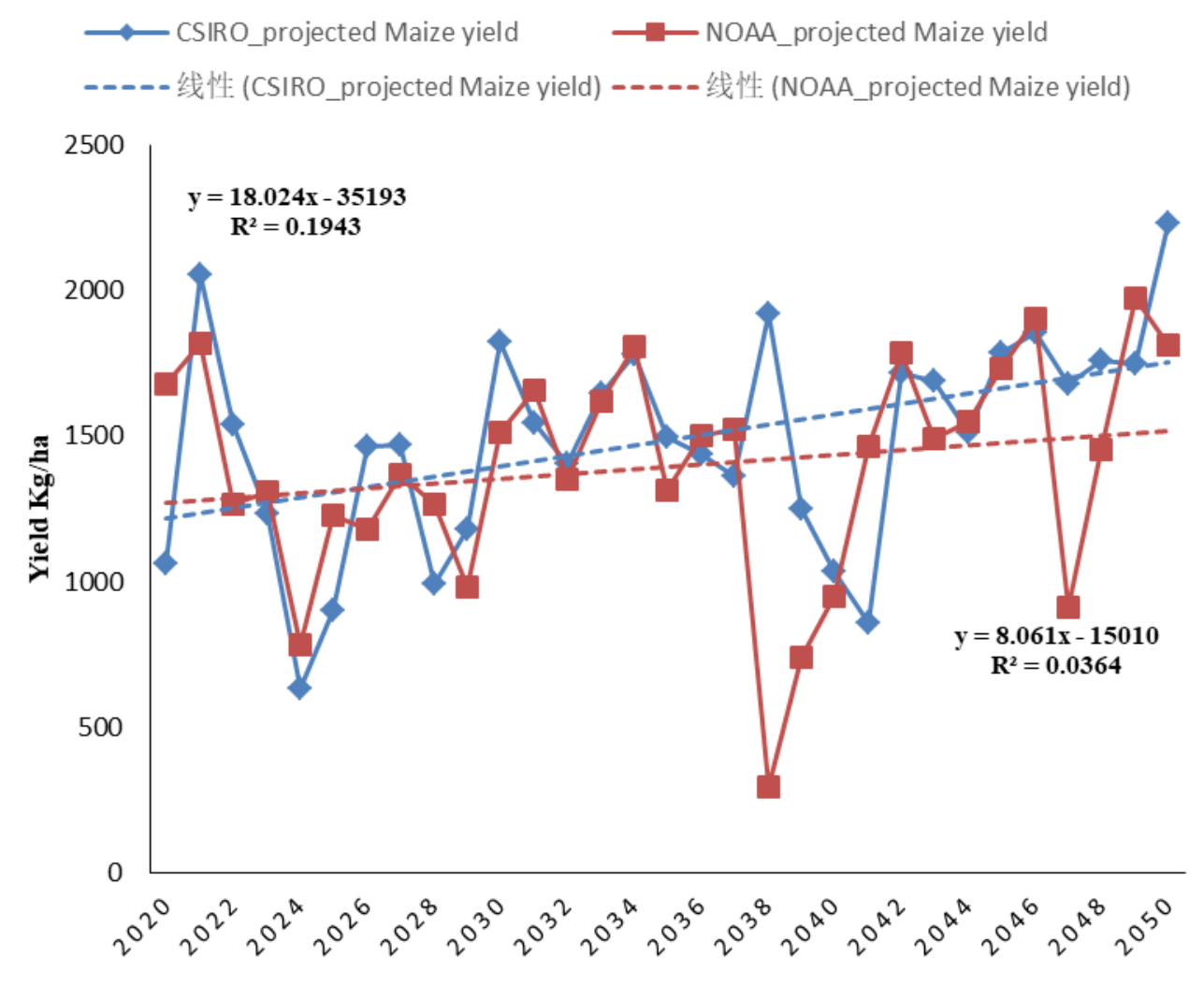

Figure 3. Projected maize yield due to annual trends in rainfall, minimum and maximum temperatures, relative humidity and sunshine duration from 2021-2050. The trends of maize in blue color is CSIRO_RCP4.5 and brown color for NOAA_RCP4.5

Contrary, the baseline (1987-2016) rice yield showed contrasting results using the same climate variables (Figure 4). The highest average rice yield (2083 kg/ha) was in 1988 and the lowest yield in 2014 with a yield of $646 \mathrm{~kg} / \mathrm{ha}$. The influence of climate variability on rice yield was seen since 1989 and showed a sharp decreasing trend towards the end of the baseline period (2016). It was observed that $50 \%$ of yield decline of rice is cause by climate variability. However, the projection showed a similar pattern as compared to maize yield with the same explanatory variables (Figure 5). Climate variability affected more on rice yield as the projection continues towards the middle of the century. Rice yield reduces drastically as seen in the annual trend under RCP4.5-NOAA from $1389 \mathrm{~kg} / \mathrm{ha}$ to $402 \mathrm{~kg} / \mathrm{ha}$ and increases for RCP4.5-CSIRO going from $786 \mathrm{~kg} / \mathrm{ha}$ to $1375 \mathrm{~kg} / \mathrm{ha}$. However, it was observed that by 2047 rice yield may reached up to $1389 \mathrm{~kg} / \mathrm{ha}$ as the highest record from RCP4.5-NOAA scenario making it more beneficial than RCP4.5-CSIRO for that year. RCP4.5-CSIRO showed a better trend in future than RCP4.5-NOAA. Some notable deviations occurred in 2031 and 2044. 


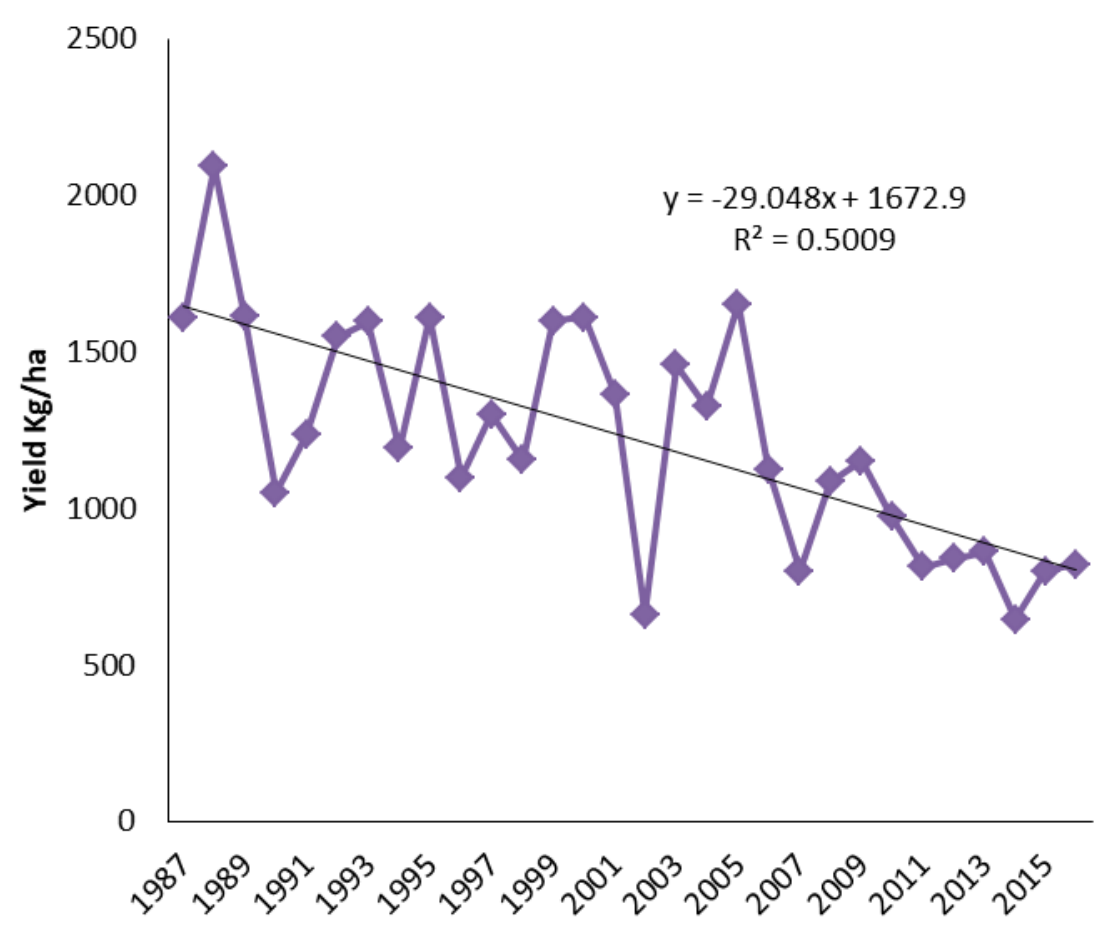

Figure 4. Baseline rice yield due to annual trends in historical rainfall, minimum and maximum temperatures, relative humidity and sunshine duration from 1987-2016

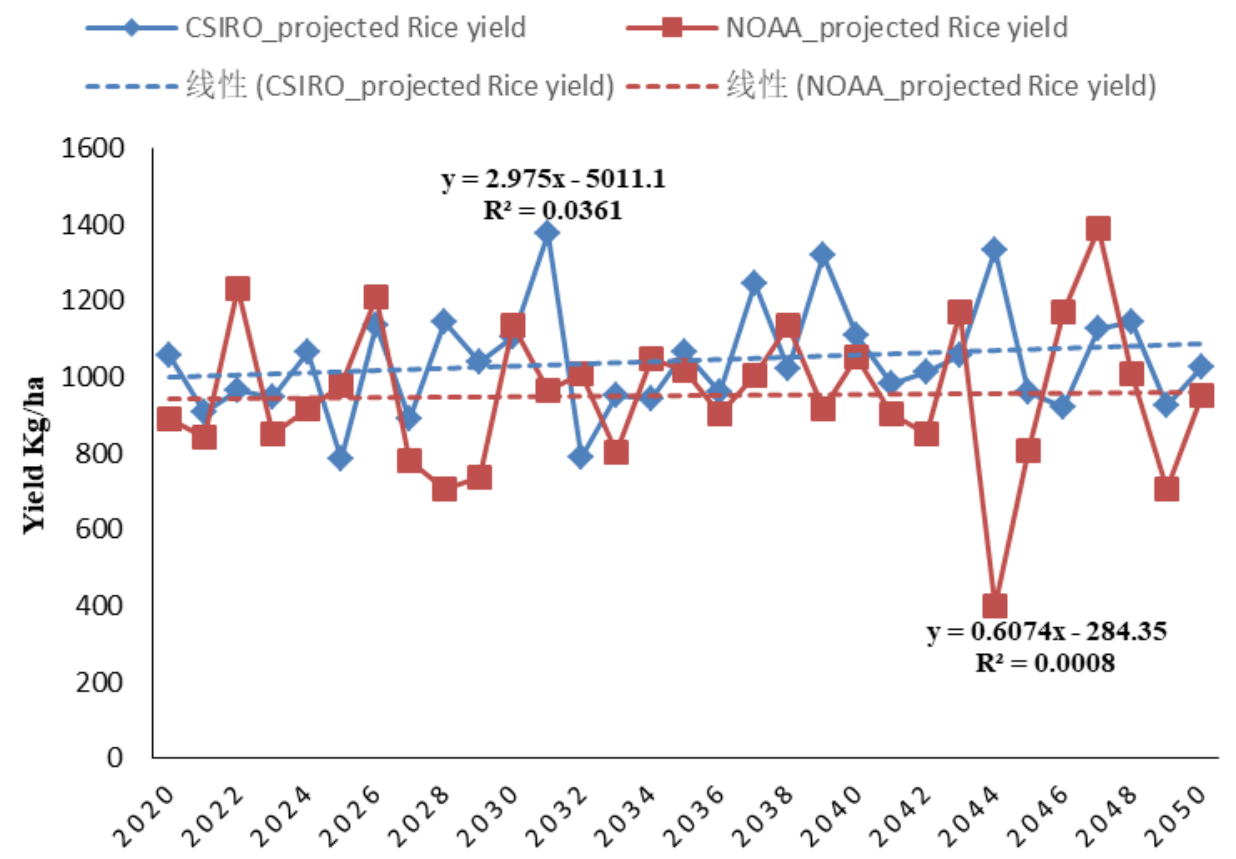

Figure 5. Projected rice yield due to annual trends in rainfall, minimum and maximum temperatures, relative humidity and sunshine duration from 2021-2050. The trends of maize in blue color is RCP 4.5-CSIRO and brown color for RCP 4.5 - NOAA 


\section{Macrothink

The average baseline yield data for maize and rice yield were $1138 \mathrm{~kg} / \mathrm{ha}$ and $1223 \mathrm{~kg} / \mathrm{ha}$ respectively. These were average yields obtained from the 30-year historical data (1987-2016). Percentage changes as compared with the projected yield were computed in (Equation 1). These changes are presented in Figure 5 and 6 for maize and rice yields respectively.

However, the 10-year temporal trends in rainfall, minimum and maximum temperatures, relative humidity and sunshine duration are assessed, for three interval-starting points in future 2021-2030, 2031,2040, 2041-250) on the yield of maize. The first decadal period from 2021-2030 under RCP4.5-NOAA showed a yield increase of $12 \%$ whilst under RCP4.5-CSIRO yield adjusted to $17 \%$. In the second decadal period (2031-2040) under RCP4.5-CSIRO had a better projection of about $31 \%$ than RCP4.5-NOAA. Similarly, during the last decadal period (2041-2050), both scnerios projected an increase in maize yield but most importantly under RCP4.5-CSIRO of about $48 \%$ depicting a positive impact within the last decadal period (Figure 5).

Contrary, the emission scenarios projected different results for rice yield as compared to maize yield in the future (Figure 6). During the period 2021-2030, RCP4.5-NOAA projected yield losses of $-23 \%$ whilst RCP4.5-CSIRO projected a decline of $-18 \%$. The subsequent decade 2031-2040 showed a slight recovery of rice yield most importantly under RCP4.5-CSIRO of about $-12 \%$, which is still inadquate. Furthermore, in the last decade, the scenarios projected a decrease in rice yield from 2041-2050. The projection by RCP4.5-NOAA showed a tremendous decrease in rice yield by $-23 \%$ and $-14 \%$ under RCP4.5-CSIRO scenario respectively. It is observed that the projected rice yield in the future showed a substantial reduction of yield loss by year 2050 .

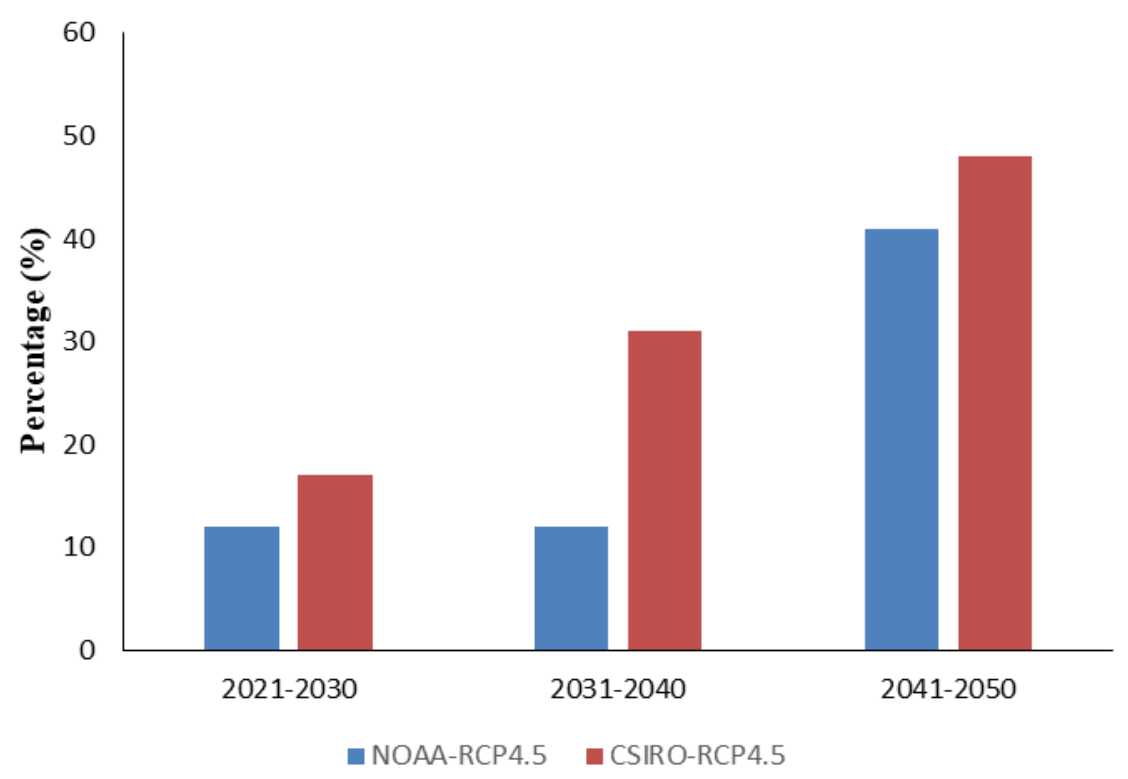

Figure 6. Barplots of maize yield losses of a given magnitude due to 10-year trends in climate variability under RCP4.5-CSIRO in brown color and RCP4.5-NOAA in blue color. Three bars are shown using three different periods (2021-2030, 2031-2040 and 2041-2050) 


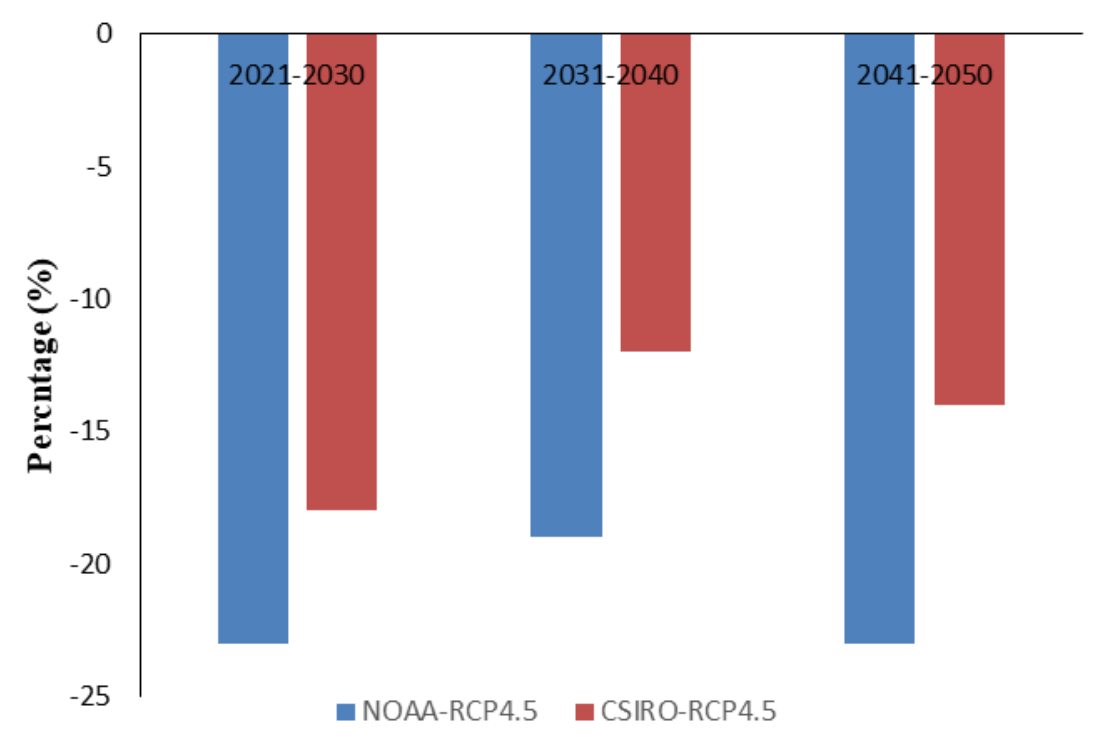

Figure 7. Barplots of rice yield losses of a given magnitude due to 10-year trends in climate variability under RCP4.5-CSIRO in brown color and RCP4.5-NOAA in blue color. Three bars are shown using three different periods (2021-2030, 2031-2040 and 2041-2050)

\section{Discussion}

The expected changes in staple food crop yields of two major crops showed that remarkable achievement from mitigation would be needed towards the middle of the century, in order to reduce the magnitude of yield losses. When comparing scenarios for projection over a long-term period (2021-2050), mitigating climate variability according to RCP4.5-CSIRO is more beneficial than RCP4.5-NOAA for maize yield. This finding is in agreement with Tebaldi and Lobell (2015) who reported that RCP4.5 is considered better for future projection of crops in terms of climate change mitigation.

However, the maize yield showed an erratic trend for the 30-year period (2021-2050) in future showing that there is an inconsistent weather pattern influencing the yield. The model is limited to only climate variables and that mitigation will enhanced the opportunity to increased yield in RCP4.5-NOAA compared to RCP4.5-CSIRO (Peters et al., 2013). Contrary, rice yield exhibits different results in terms of model projection in the future. This could be because rice growing ecologies are hydrophilic environments and any chances of moisture deficiency will affect the yield, which could have triggered model inconsistency. This finding was similar to a study conducted by Kropff et al. (2001) who reported that rice could be vulnerable to erratic rainfall below normal during growing season and will have a negative impact during tillering. This model results may not show the entire picture since from this angle, the model results may showed nonlinearities hence the confounding variables like soil fertility, pest, disease and climate extremes (drought and flood) which may likely influence crop yields are not included in the model (Jing et al., 2012).

For rice yield assessment, losses of yield is substantial significant and increases towards the 
mid of the century (2050). A projected decrease in rice yield by the mid-century (2050) showed that, climate change and variability might likely have impact on food security; hence, rainfed rice production may not be feasible to supply the growing population food demand. In a similar study, Dawson et al. (2014) concluded that "under the 2050 scenarios, wheat, maize and soybean were projected to have an overall mean reduction of up to 40, 50 and $50 \%$ respectively when compared to baseline productions with some variation between the GCMs and regions spatially".

Concerning the findings, rice yield is expected to decrease in the future for the locations within the study area by 2050 for all scnerios RCP4.5-CSIRO and RCP4.5-NOAA. Such information is vital hence, there is no single factor responsible for yield reduction and farmers' decision to adapt to such changes is inadquate. Even though some studies claimed that cereal yields will be reduce in the future, the results for maize yield showed an increase in the future for both scenarios (Cairns et al., 2013; Fitzgerald, 2016). This study contradict with the findings of Cairns et al. (2013) who claimed that, any accumulated increase in mean temperatures above $30^{\circ} \mathrm{C}$ in future may lead to a reduction of maize yields. The increased in maize yield as seen in both GCMs (RCP4.5-CSIRO and RCP4.5-NOAA) scenarios could have been some coping mechanism praticed by farmers using improved varieties. Increased in the emission scenarios in future may lead to global warming, which could trigger sea level rise, this may affect coastal rice growing ecologies. From this study, it was observed that rice yield will decrease drastically towards the mid-centuary which might have cause due to sea level rise affecting coastal rice growing ecologies in future (Clark et al., 2016). For future adaptation, farmers need to integrate many farming strategies including the mitigation of climate risk. However, barriers impeding poor farmers and policy implementation on adaptation in sub-Saharan Africa still presents a daunting challenge (Antwi-Agyei et al., 2013).

\section{Conclusions and Recommendations}

From the current study, it is concluded that rice and maize yield will reduce because of projected increase in climate variables. Fluctuation of yields was observed over decadal periods from 2021-2050, which showed the fluctuation of climate in the future. Higher yield losses impacted by climate pattern projected by both RCP4.5-CSIRO and RCP4.5-NOAA was seen towards mid-century (2050) for rice indicating future climate risk on rice yield. In this study, our findings did not account for the non-climate variables therefore cannot make any conclusion that yield variations are attributed to only climate variability. Future predictions should therefore consider climate and non-climate variables. The benefits of climate change adaptation to offset the negative effect of climate change is still ambiguous and that required for additional research in order to benefit from the positive impact as noted by several authors (Antwi-Agyei et al., 2013; Vermeulen et al., 2013). Further research should be carried out to develop new improved rice and maize cultivars to offset the negative effects of climate variability in future. 


\section{Acknowledgements}

This paper is one of the outcomes of $\mathrm{PhD}$ thesis submitted to the Kwame Nkurumah University of Science and Technology under the sponsorship of BMBF through West Africa Science Service Centre on Climate Change and Adapted Land Use (WASCAL), CCLU GRP program. The authors are indebted to World Climate Research Programme's Working Group on Regional Climate, and the Working Group on Coupled Modelling, former coordinating body of CORDEX and responsible panel for CMIP5 for providing future climate data.

\section{References}

Akon-yamga, G., Boadu, P., Obiri, B. D., Amoako, J., \& Mboob, F. J. (2011). Agricultural Innovations for Climate Change Adaptation and Food Security in Africa: The Cases of Ghana and The Gambia. Afican Technology Policy Studies Network, 10(11), 56.

Al-Amin, A. Q., \& Ahmed, F. (2016). Food Security Challenge of Climate Change: An Analysis for Policy Selection. Futures, 83, 50-63.

https://doi.org/10.1016/j.futures.2016.04.002

Antwi-Agyei, P., Dougill, A. J., Fraser, E. D. G., \& Stringer, L. C. (2013). Characterising the nature of household vulnerability to climate variability: Empirical evidence from two regions of Ghana. Environment, Development and Sustainability, 15(4), 903-926.

https://doi.org/10.1007/s10668-012-9418-9

Awoye, O. H. R., Pollinger, F., Agbossou, E. K., \& Paeth, H. (2017). Agricultural and Forest Meteorology Dynamical-statistical projections of the climate change impact on agricultural production in Benin by means of a cross-validated linear model combined with Bayesian statistics. Agricultural and Forest Meteorology, 234-235, 80-94.

https://doi.org/10.1016/j.agrformet.2016.12.010

Bojang, P. O., Yu, P., Yang, T., \& Kuo, C. (2016). Optimal Cropping Patterns for Profit Maximization Using a Linear Programming Model : A Case Study in Njawara Village, The Gambia, Hydro-Science \& Engineering for Environmental Resilience, 10-13.

Cairns, J. E., Hellin, J., Sonder, K., Araus, J. L., Macrobert, J. F., Thierfelder, C., \& Prasanna, B. M. (2013). Adapting maize production to climate change in sub-Saharan Africa, Food Security, 345-360. https://doi.org/10.1007/s12571-013-0256-x

Clark, P. U., Shakun, J. D., Marcott, S. A., Mix, A. C., Eby, M., Kulp, S., ... Plattner, G. K. (2016). Consequences of twenty-first-century policy for multi-millennial climate and sea-level change. Nature Climate Change, 6(4), 360-369.

https://doi.org/10.1038/nclimate2923

Conceição, P., Levine, S., Lipton, M., \& Warren-Rodríguez, A. (2016). Toward a food secure future: Ensuring food security for sustainable human development in Sub-Saharan Africa. Food Policy, 60, 1-9. https://doi.org/10.1016/j.foodpol.2016.02.003

Dawson, T. P., Perryman, A. H., \& Osborne, T. M. (2014). Modelling impacts of climate change on global food security. Climate Change. 
Fitzgerald, T. (2016). The Impact of Climate Change, Plant Genomics and Climate Change, $1-13$.

GBoS. (2013). The Gambia 2013 Population and Housing Census Preliminary Results. The Gambia Bureau of Statistics, 23. Retrieved from www.gbos.gov.gm

Godfray, H. C. J., Beddington, J. R., Crute, I. R., Haddad, L., Lawrence, D., Muir, J. F., ... Toulmin, C. (2010). Food Security: The Challenge of, 327(February), Food Security, $812-818$.

Gupta, R., \& Mishra, A. (2019). Climate change induced impact and uncertainty of rice yield of agro-ecological zones of India. Agricultural Systems, 173(October 2018), 1-11. https://doi.org/10.1016/j.agsy.2019.01.009

Hayes, J., Roth, M., \& Zepeda, L. (1997). Tenure securoty, investment and productivity in Gambian agriculture: a genaralized probit analysis. American Journal of Agricultural Economics, 79(May), 369-382. https://doi.org/10.2307/1244136

IPCC. (2007). Climate change 2007 : impacts, adaptation and vulnerability: Working Group II contribution to the Fourth Assessment Report of the IPCC Intergovernmental Panel on Climate Change. Working Group II Contribution to the Intergovernmental Panel on Climate Change Fourth Assessment Report, 1(July), 976.

Jha, P. K., Athanasiadis, P., Gualdi, S., Trabucco, A., Mereu, V., Shelia, V., \& Hoogenboom, G. (2019). Using daily data from seasonal forecasts in dynamic crop models for yield prediction: A case study for rice in Nepal's Terai. Agricultural and Forest Meteorology, 265(November 2018), 349-358. https://doi.org/10.1016/j.agrformet.2018.11.029

Jing, Q., Conijn, S. J. G., Jongschaap, R. E. E., \& Bindraban, P. S. (2012). Modeling the productivity of energy crops in different agro-ecological environments. Biomass and Bioenergy, 46, 618-633. https://doi.org/10.1016/j.biombioe.2012.06.035

Kisekka, I., Araya, A., Martorano, L. G., Luedeling, E., Hoogenboom, G., \& Hadgu, K. M. (2015). Assessment of maize growth and yield using crop models under present and future climate in southwestern Ethiopia. Agricultural and Forest Meteorology, 214-215, 252-265.

Kropff, M. J., Bouma, J., \& Jones, J. W. (2001). Systems approaches for the design of sustainable agro-ecosystems, Agricultural Systems, 70, 369-393.

https://doi.org/10.1016/S0308-521X(01)00052-X

Kropff, R. B. M. M. J., Horie, T., \& Bacheletd, D. (1997). Simulating the Impact of Climate Change on Rice Production in Asia and Evaluating Options for Adaptation, Agricultural Systems, 54(3), 399-425. https://doi.org/10.1016/S0308-521X(95)00060-I

Liu, Z. J., Yang, X. G., Hubbard, K. G., \& Lin, X. M. (2012). Maize potential yields and yield gaps in the changing climate of northeast China, Global Change Biology, 1-14. https://doi.org/10.1111/j.1365-2486.2012.02774.x

Lobell, D. B., \& Burke, M. B. (2010). On the use of statistical models to predict crop yield 
responses to climate change. Agricultural and Forest Meteorology, 150(11), 1443-1452. https://doi.org/10.1016/j.agrformet.2010.07.008

Lobell, D. B., \& Field, C. B. (2007). Global scale climate-crop yield relationships and the impacts of recent warming. Environmental Research Letters, 2(1).

https://doi.org/10.1088/1748-9326/2/1/014002

Lobell, D. B., \& Gourdji, S. M. (2012). The Influence of Climate Change on Global Crop Productivity. Plant Physiology, 160(4), 1686-1697. https://doi.org/10.1104/pp.112.208298

Maracchi, G., Sirotenko, O., \& Bindi, M. (2005). Impacts of present and future climate variability on agriculture and forestry in the temperate regions: Europe. Increasing Climate Variability and Change: Reducing the Vulnerability of Agriculture and Forestry. Climatic Change, 70, 1-3. https://doi.org/10.1007/1-4020-4166-7_6

Mereu, V., Carboni, G., Gallo, A., Cervigni, R., \& Spano, D. (2015). Impact of climate change on staple food crop production in Nigeria. Climate Change, 132(2), 321-336. https://doi.org/10.1007/s10584-015-1428-9

Nakano, Y., Tanaka, Y., \& Otsuka, K. (2014). To What Extent Do Improved Practices Increase Productivity of Small-Scale Rice Cultivation in A Rain-fed Area? : Evidence from Tanzania. National Graduate Institute for Policy Studies, 14(November), 1-28.

Nigatu, G., Hansen, J., Childs, N., \& Seeley, R. (2017). Sub-Saharan Africa Is Projected To Be the Leader in Global Rice Imports Highlights : United States Department of Agriculture Economic Research Service

Oort, P. A. J. Van, \& Zwart, S. J. (2018). Impacts of climate change on rice production in Africa and causes of simulated yield changes, (July 2017), Global Change Biology, 1029-1045. https://doi.org/10.1111/gcb.13967

Peters, G. P., Andrew, R. M., Boden, T., Canadell, J. G., Ciais, P., Quéré, C. Le, ... Wilson, C. (2013). The challenge to keep global warming below $2^{\circ} \mathrm{C}, 3(J a n u a r y)$, Nature Climate Change, 2011-2013.

Sanneh, E. S., Hu, A. H., Hsu, C. W., \& Njie, M. (2014). Prioritization of climate change adaptation approaches in the Gambia. Mitigation and Adaptation Strategies for Global Change, 19(8), 1163-1178. https://doi.org/10.1007/s11027-013-9465-z

Sheahan, M., \& Barrett, C. B. (2017). Food loss and waste in Sub-Saharan Africa: A critical review. Food Policy, 70, 1-12. https://doi.org/10.1016/j.foodpol.2017.03.012

Sheng, Y., \& Song, L. (2019). Agricultural production and food consumption in China: A long-term projection. China Economic Review, 53(August 2018), 15-29.

https://doi.org/10.1016/j.chieco.2018.08.006

Shiu, Y.-S., \& Chuang, Y.-C. (2019). Yield Estimation of Paddy Rice Based on Satellite Imagery: Comparison of Global and Local Regression Models. Remote Sensing, 11(2).

Sissoko, K., van Keulen, H., Verhagen, J., Tekken, V., \& Battaglini, A. (2011). Agriculture, 
livelihoods and climate change in the West African Sahel. Regional Environmental Change, 11(SUPPL. 1), 119-125. https://doi.org/10.1007/s10113-010-0164-y

Srivastava, A. K., Mboh, C. M., Zhao, G., Gaiser, T., \& Ewert, F. (2018). Climate change impact under alternate realizations of climate scenarios on maize yield and biomass in Ghana. Agricultural Systems, 159(March), 157-174. https://doi.org/10.1016/j.agsy.2017.03.011

Tebaldi, C., \& Lobell, D. (2015). Estimated impacts of emission reductions on wheat and maize crops. Climatic Change, 146(3-4), 533-545.

Traore, B., Descheemaeker, K., Wijk, M. T. Van, Corbeels, M., Supit, I., \& Giller, K. E. (2017). Field Crops Research Modelling cereal crops to assess future climate risk for family food self-sufficiency in southern Mali. Field Crops Research, 201, 133-145. https://doi.org/10.1016/j.fcr.2016.11.002

Vermeulen, S. J., Challinor, A. J., Thornton, P. K., Campbell, B. M., Eriyagama, N., Vervoort, J. M., ... Smith, D. R. (2013). Addressing uncertainty in adaptation planning for agriculture. Proceedings of the National Academy of Sciences of the United States of America, 110(21), 8357-8362. https://doi.org/10.1073/pnas.1219441110

Waha, K., Müller, C., \& Rolinski, S. (2013). Separate and combined effects of temperature and precipitation change on maize yields in sub-Saharan Africa for mid- to late-21st century. Global and Planetary Change, 106, 1-12. https://doi.org/10.1016/j.gloplacha.2013.02.009

Waongo, M., Laux, P., \& Kunstmann, H. (2015). Agricultural and Forest Meteorology Adaptation to climate change: The impacts of optimized planting dates on attainable maize yields under rainfed conditions in Burkina Faso. Agricultural and Forest Meteorology, 205, 23-39. https://doi.org/10.1016/j.agrformet.2015.02.006

Wei, X., Declan, C., Erda, L., Yinlong, X., Hui, J., Jinhe, J., ... Yan, L. (2009). Future cereal production in China: The interaction of climate change, water availability and socio-economic scenarios, Global Environmental Change, 19, 34-44.

https://doi.org/10.1016/j.gloenvcha.2008.10.006

\section{Copyright Disclaimer}

Copyright for this article is retained by the author(s), with first publication rights granted to the journal.

This is an open-access article distributed under the terms and conditions of the Creative Commons Attribution license (http://creativecommons.org/licenses/by/4.0/). 